ARTICLE

DOI: $10.1038 / s 41467-018-04771-y$

\title{
An anionic phthalocyanine decreases NRAS expression by breaking down its RNA G-quadruplex
}

Keiko Kawauchi id 1, Wataru Sugimoto', Takatoshi Yasui ${ }^{1}$, Kohei Murata ${ }^{1}$, Katsuhiko Itoh', Kazuki Takagi', Takaaki Tsuruoka (1) ${ }^{1}$, Kensuke Akamatsu', Hisae Tateishi-Karimata ${ }^{2}$, Naoki Sugimoto ${ }^{2}$ \& Daisuke Miyoshi (i) ${ }^{1}$

Aberrant activation of RAS signalling pathways contributes to aggressive phenotypes of cancer cells. The RAS-targeted therapies for cancer, therefore, have been recognised to be effective; however, current developments on targeting RAS have not advanced due to structural features of the RAS protein. Here, we show that expression of NRAS, a major isoform of RAS, can be controlled by photo-irradiation with an anionic phthalocyanine, ZnAPC, targeting NRAS mRNA. In vitro experiments reveal that ZnAPC binds to a G-quadruplex-forming oligonucleotide derived from the 5'-untranslated region of NRAS mRNA even in the presence of excess double-stranded RNA, which is abundant in cells, resulting in selective cleavage of the target RNA's G-quadruplex upon photo-irradiation. In line with these results, upon photo-irradiation, ZnAPC decreases NRAS mRNA and NRAS expression and thus viability of cancer cells. These results indicate that ZnAPC may be a prominent photosensitiser for a molecularly targeted photodynamic therapy for cancer.

\footnotetext{
${ }^{1}$ Faculty of Frontiers of Innovative Research in Science and Technology (FIRST), Konan University, Kobe 650-0047, Japan. ${ }^{2}$ Frontier Institute for Biomolecular Engineering Research (FIBER), Konan University, Kobe 650-0047, Japan. Correspondence and requests for materials should be addressed to K.K. (email: kawauchi@center.konan-u.ac.jp) or to D.M. (email: miyoshi@center.konan-u.ac.jp)
} 
$\mathrm{P}$ hotodynamic therapy (PDT) is being widely recognised as a minimally invasive cancer treatment ${ }^{1-4}$. The photosensitisers used for PDT mostly consist of porphyrins and their analogues such as phthalocyanines, which possess low cytotoxicity in the dark and preferentially accumulate in tumour tissue $^{3-6}$. Moreover, PDT typically uses light in a wavelength range of $600-800 \mathrm{~nm}$ to avoid interference by endogenous chromophores $^{3,7-9}$. A photosensitiser absorbs light and subsequently relaxes to the first excited singlet state. Then, the singlet state undergoes conversion to the triplet state when it does not go back to the ground state. An electronic energy of the photosensitiser in the triplet state transfers to oxygen, resulting in formation of cytotoxic reactive oxygen species (ROS) such as singlet oxygen $\left({ }^{1} \mathrm{O}_{2}\right)$ and superoxide $\left(\mathrm{O}_{2}{ }^{-}\right)$. Thus, cancer cells are killed by these photosensitisers in response to light exposure. Recently, in PDT, several photosensitisers targeting key molecules such as KRAS and Ki-67, which are associated with aggressive cancer cells, have been explored ${ }^{10-13}$.

In cancer cells, commonly occurring missense mutations in three members of the RAS family genes (HRAS, KRAS and NRAS) result in their constitutive activation. In addition to these mutations, the overexpression and aberrant activation of receptor tyrosine kinases, such as epidermal growth factor receptor (EGFR) and hepatocyte growth factor receptor (HGFR/c-Met), lead to RAS hyperactivation. Because RAS hyperactivation promotes abnormal cell proliferation and metastasis, cancer therapies that involve drugs that target RAS are widely believed to be effective. Nonetheless, the drugs that directly target a RAS protein could not be identified for a long time because of the structural features of the RAS proteins ${ }^{14}$. It is known that in cancer cells, NRAS and KRAS are often hyperactivated in comparison with HRAS and therefore NRAS and KRAS are much more important therapeutic targets in cancer when compared to HRAS $^{14,15}$. Although several potential small molecules that target the mutant KRAS G12 protein have been reported ${ }^{16-18}$, effective inhibitors of NRAS have yet to be identified.

G-quadruplexes are non-canonical structures of nucleic acids formed by guanine-rich oligonucleotides with four Hoogsteenpaired coplanar guanines, called a $\mathrm{G}$-quartet ${ }^{19}$. The nucleotide sequences containing $\mathrm{G}_{2-5}-\mathrm{N}_{1-7}-\mathrm{G}_{2-5}-\mathrm{N}_{1-7}-\mathrm{G}_{2-5}-\mathrm{N}_{1-7}-\mathrm{G}_{2-5}$, where $\mathrm{G}$ (stem) is guanine and $\mathrm{N}$ (loop) may be any nucleotide, can form G-quadruplexes ${ }^{20}$. G-quadruplex-forming sequences are found in telomeres and are enriched in the promoters and untranslated regions (UTRs) of genes, especially cancer-related genes such as NRAS, VEGF and BCL2 $2^{20-27}$. Because DNA G-quadruplexes in the promoter often suppress gene expression through impairment of the initiation of transcription ${ }^{28}$, Balasubramanian's and other groups have demonstrated that formation of G-quadruplexes in mRNAs regulates gene expression ${ }^{21,27,29-31}$. It has also been reported that RNA G-quadruplexes in the 5' UTR repress translation by interfering with the recruitment of the pre-initiation complex $^{32}$. The gene expression regulated by formation of G-quadruplexes is assumed to be associated with cancer development and progression ${ }^{27}$. This notion has been supported by a growing body of evidence on G-quadruplex ligands as potential anticancer drugs ${ }^{31,33-35}$. Yet, there are no approved anticancer
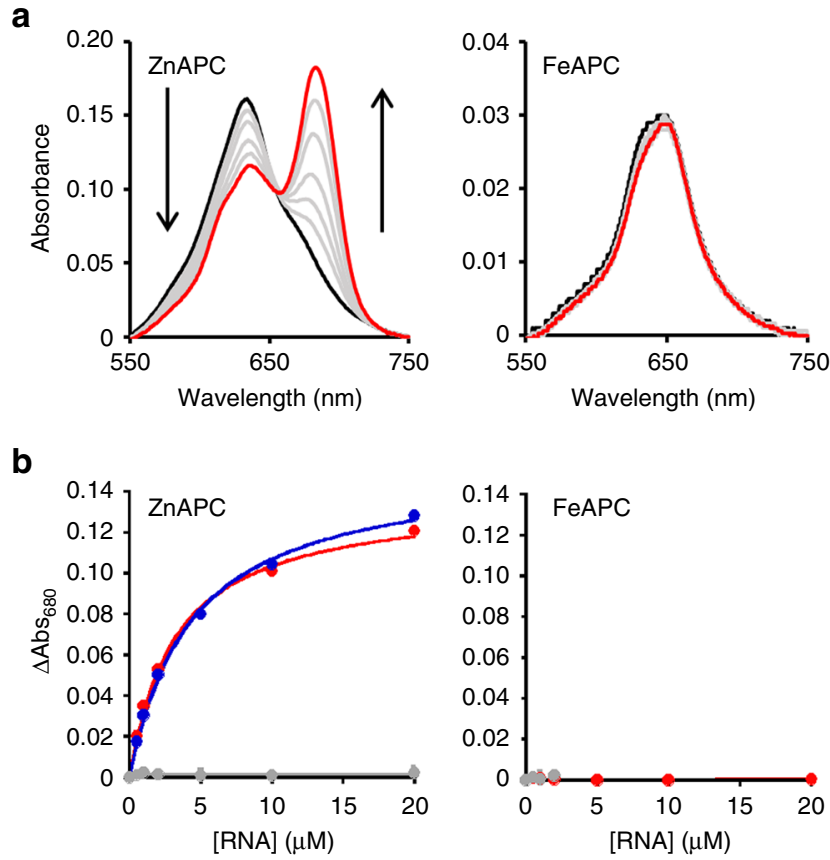

C

\begin{tabular}{cccccc}
\hline & ZnAPC & ZnAPC $^{*}$ & FeAPC & NiAPC & CuAPC \\
\hline$K_{\mathrm{d}}(\mu \mathrm{M})$ & $3.1 \pm 0.3$ & $4.3 \pm 0.04$ & N/A & $3.9 \pm 0.5$ & $2.4 \pm 0.2$ \\
\hline
\end{tabular}
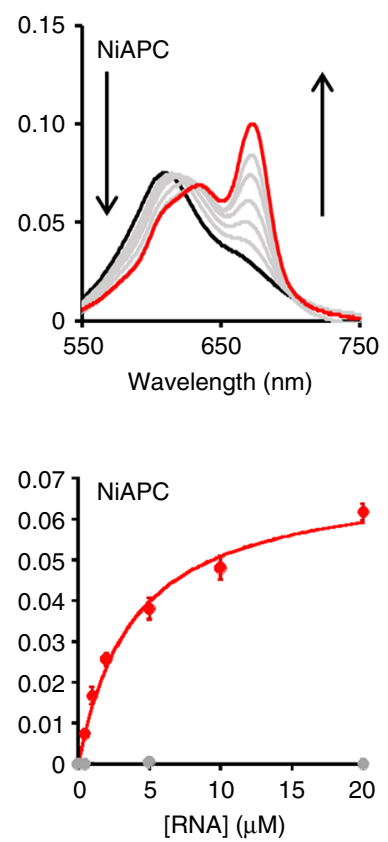
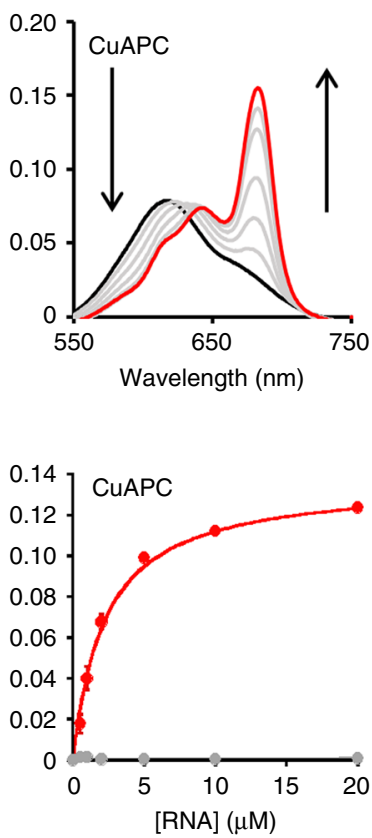

${ }^{*}$ In the presence of $100 \mu \mathrm{M}$ dsRNA

Fig. $1 \mathrm{ZnAPC}, \mathrm{NiAPC}$ and CuAPC bind to the NRAS RNA G-quadruplex. a VIS absorbance spectra of $2 \mu \mathrm{M}$ ZnAPC, FeAPC, NiAPC or CuAPC with 0, 0.5, 1 , $2,5,10$ or $20 \mu \mathrm{M}$ NRAS RNA at $25^{\circ} \mathrm{C}$. The spectra with 0 and $20 \mu \mathrm{M}$ NRAS RNA are highlighted in black and red, respectively. $\mathbf{b}$ Plots of $\triangle$ Absorbance at $680 \mathrm{~nm}$ (=absorbance with NRAS RNA minus absorbance without NRAS RNA) of ZnAPC, FeAPC, NiAPC or CuAPC vs. the concentration of NRAS RNA (red) or dsRNA (grey). The plots of $\triangle$ Absorbance in the presence of $100 \mu \mathrm{M}$ dsRNA are also given in the ZnAPC spectrum (blue). Error bars represent mean $\pm \mathrm{SD} ; n=3$. c $K_{d}$ values of the APCs with NRAS RNA at $25^{\circ} \mathrm{C}$ 

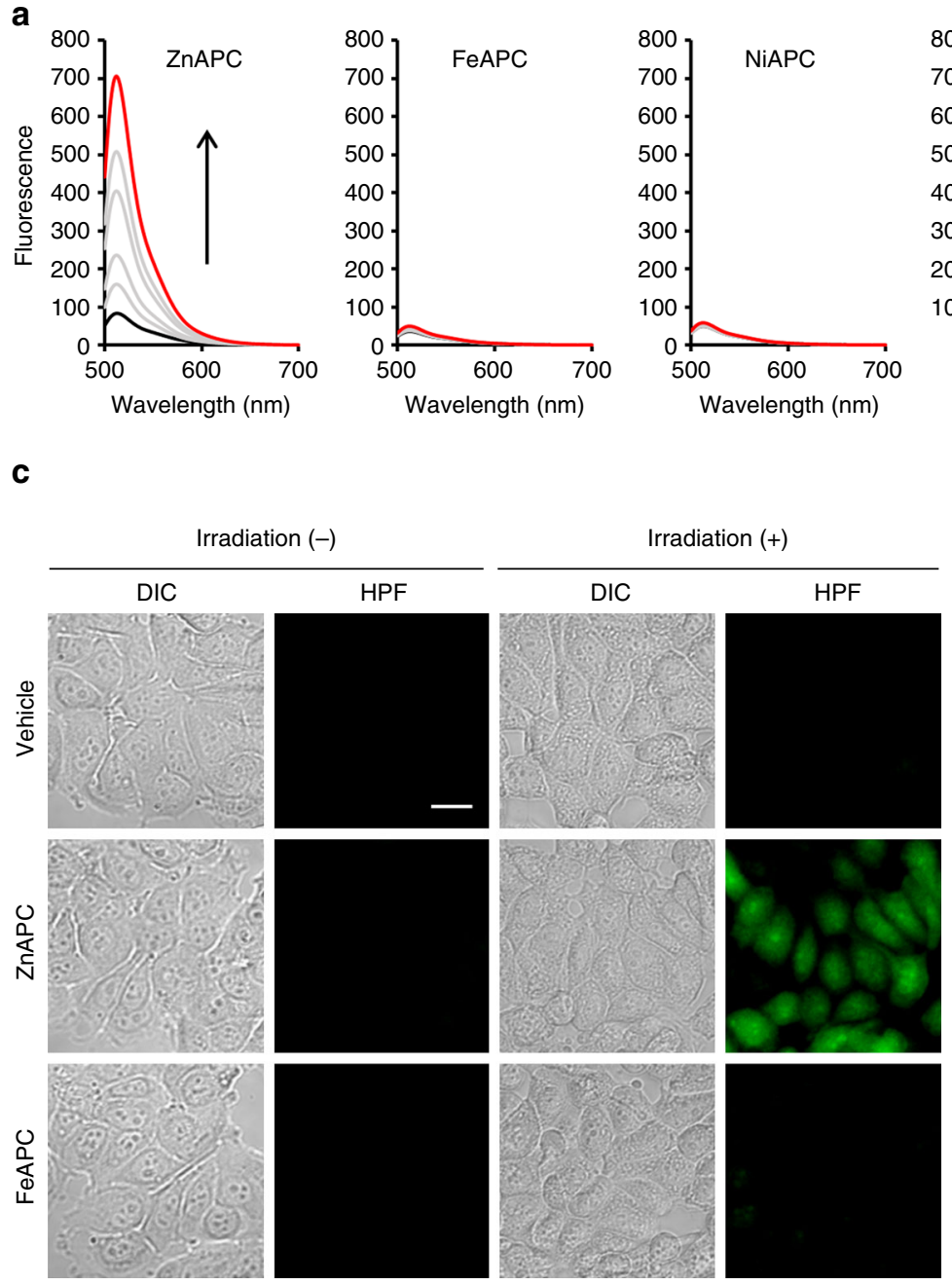
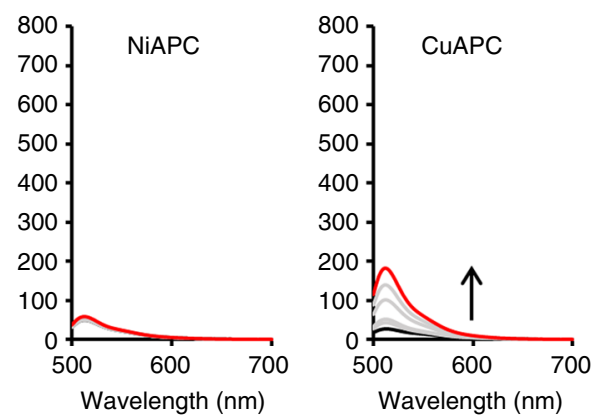

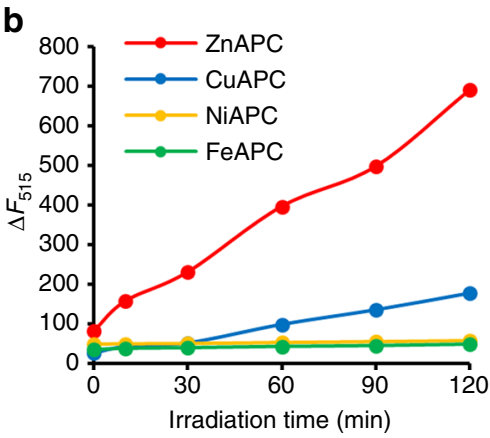

d

e

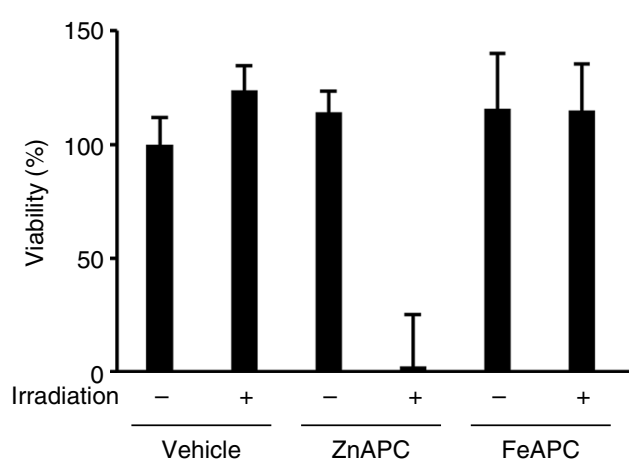

Fig. $2 \mathrm{ZnAPC}$ induces ROS production in vitro and in cells. a Fluorescence spectra of $10 \mu \mathrm{M}$ HPF as an ROS indicator in the presence of $2 \mu \mathrm{M}$ ZnAPC, $\mathrm{FeAPC}, \mathrm{NiAPC}$ or CUAPC at $25^{\circ} \mathrm{C}$. Excitation wavelength was $490 \mathrm{~nm}$. The spectra at irradiation time points 0 and 120 min are highlighted in black and red, respectively. $\mathbf{b}$ Plots of the change in fluorescence intensity of HPF at $515 \mathrm{~nm}$ during the photo-irradiation. $\mathbf{c}$ Evaluation of ROS levels by means of HPF in MCF-7 cells treated with ZnAPC or FeAPC after photo-irradiation for $1 \mathrm{~h}$. DIC images of cells and fluorescent images of HPF are presented. Scale bar, 20 $\mu \mathrm{m}$. d The mean fluorescence intensity of HPF was quantified. Relative fluorescence intensities are shown, and each bar represents mean \pm SD for 10 images. e Cells pre-treated with ZnAPC or FeAPC for $1 \mathrm{~h}$ were incubated for $24 \mathrm{~h}$ after photo-irradiation for $2 \mathrm{~h}$. The number of viable cells was determined by Trypan Blue exclusion-based cell staining. The number of treated cells was normalised to that of untreated cells. Each bar represents mean \pm SD; $n=3$. All intracellular experiments were conducted with $10 \mu \mathrm{M} \mathrm{HPF}, 10 \mu \mathrm{M}$ ZnAPC or $10 \mu \mathrm{M}$ FeAPC

drugs targeting DNA or RNA G-quadruplexes. This is at least partly because of non-specific binding of known ligands of Gquadruplexes to DNA and RNA duplexes, which are the most abundant structures of genomic DNA and coding and non-coding transcripts, respectively ${ }^{36}$. Moreover, almost all known ligands bind to a target G-quadruplex in a reversible manner, leading to only a transient effect of the ligand on the respective gene expression. The expression of cancer-related proteins regulated by formation of a G-quadruplex, including NRAS, can be effectively controlled if a ligand can not only bind reversibly but also attack irreversibly DNA and RNA G-quadruplexes.

Here, we demonstrate that an anionic phthalocyanines with $\mathrm{Zn}^{2+}$ (ZnAPC) not only binds but also cleaves a G-quadruplexforming $5^{\prime}$ UTR of the NRAS mRNA G-quadruplex after photoirradiation and induces cell death. It is next shown that $\mathrm{ZnAPC}$ is a capable photosensitiser for direct transfer of energy to NRAS
mRNA and induces its breakdown upon photo-irradiation even under low-oxygen conditions, which are defining feature of solid tumours. The approach in this study holds promise for a molecularly targeted PDT for cancer.

\section{Results}

ZnAPC binds to the G-quadruplex derived from NRAS mRNA. Some small molecules have been found to bind to a G-quadruplex in a selective manner ${ }^{37-39}$. Among these molecules, anionic phthalocyanines (APCs) coordinating $\mathrm{Ni}^{2+}$ (NiAPC) or $\mathrm{Cu}^{2+}$ (CuAPC) bind to DNA G-quadruplexes derived from human telomeric $\mathrm{DNA}^{40,41}$. According to these results, we hypothesised that anionic phthalocyanine derivatives can control NRAS expression by photo-irradiation. Because a phthalocyanine coordinating $\mathrm{Zn}^{2+}$ has a high photosensitising ability among phthalocyanine derivatives ${ }^{3}$, we used anionic phthalocyanines, 
a

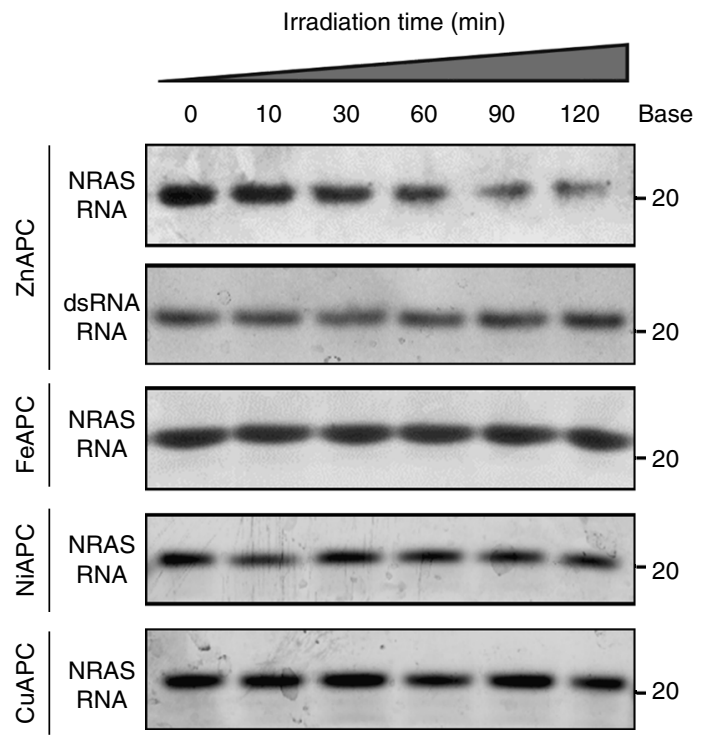

d

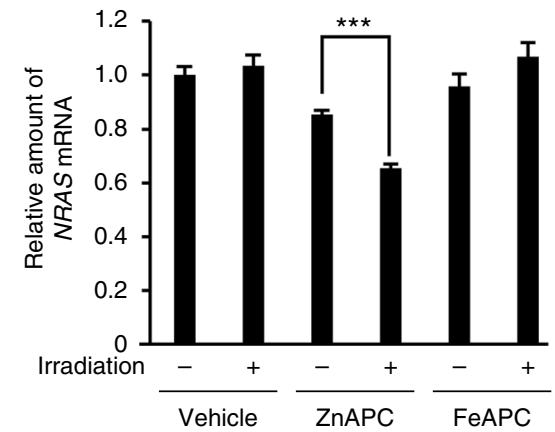

b

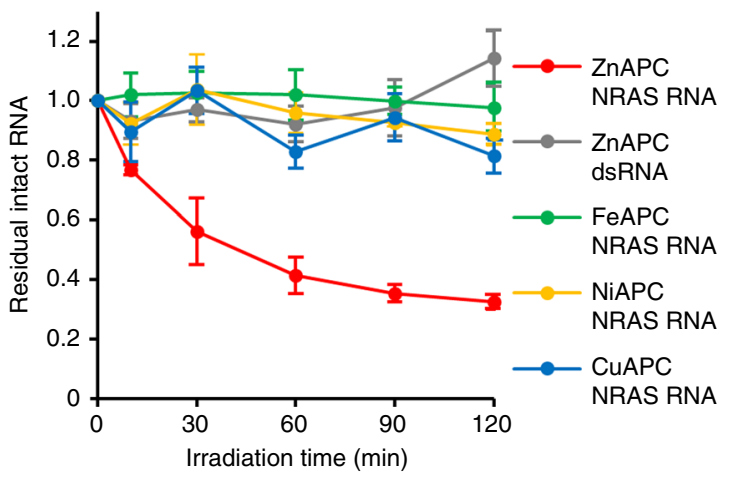

C

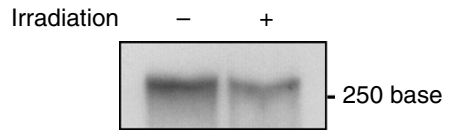

e

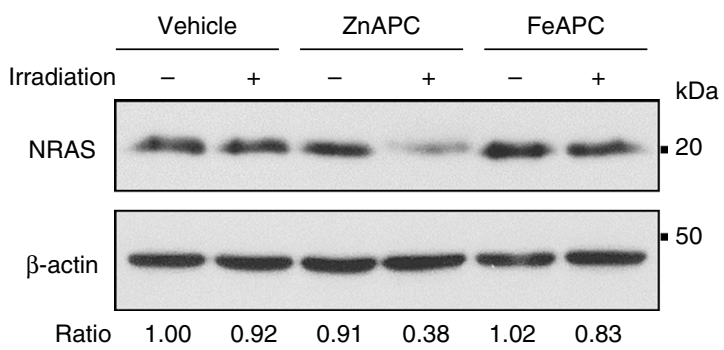

Fig. $3 \mathrm{ZnAPC}$ decreases the amount of NRAS mRNA. a Denaturing polyacrylamide gel electrophoresis (10\% gel) of $0.1 \mu \mathrm{M}$ NRAS RNA or dsRNA in the presence of $2 \mu \mathrm{M} Z n A P C, F e A P C, N i A P C$ or CuAPC after photo-irradiation for the indicated periods at $25^{\circ} \mathrm{C}$. $\mathbf{b}$ Residual intact RNA after photo-irradiation of NRAS RNA and dsRNA in the presence of APCs. Error bars represent mean $\pm S D ; n=3$. c $0.1 \mu \mathrm{M}$ NRAS F-RNA labelled with DIG in the presence of $2 \mu \mathrm{M}$ ZnAPC before and after photo-irradiation for 120 min were analysed by electrophoresis in a $15 \%$ denaturing polyacrylamide gel. The RNA was detected with antibody against DIG. d, e Cells pre-treated with $10 \mu \mathrm{M}$ ZnAPC or FeAPC together with $1 \mu \mathrm{g} \mathrm{ml}^{-1}$ actinomycin D, which inhibits de novo mRNA synthesis, for $1 \mathrm{~h}$ were photo-irradiated for $2 \mathrm{~h}$. $\mathbf{d}$ The amount of NRAS mRNA was evaluated by real-time PCR. Each bar represents mean \pm SD; $n=3$. For statistical significance, an unpaired $t$-test was performed. ${ }^{\star \star \star} p<0.0001$. e The cells were incubated for $5 \mathrm{~h}$ after photo-irradiation. The cell extracts were subjected to immunoblot analysis with antibodies against NRAS; $\beta$-actin served as a loading control. Blots of NRAS and $\beta$-actin were quantified, and the relative values of NRAS are shown

ZnAPC with zinc as a coordinated metal in addition to NiAPC, $\mathrm{CuAPC}$ and FeAPC with iron as a coordinated metal.

Because RNA is more abundant than its corresponding DNA in the cell, firstly, we evaluated the binding affinity of APCs for NRAS RNA, which is a parallel G-quadruplex-forming RNA oligonucleotide derived from the $5^{\prime}$ UTR of NRAS mRNA (the nucleotide sequence and circular dichroism (CD) spectrum are shown in Supplementary Table 1 and Supplementary Figure 1, respectively). Figure 1a shows the visible (VIS) absorption spectra of $2 \mu \mathrm{M}$ APCs in the presence of various concentrations of NRAS RNA. In the case of ZnAPC, a broad absorption peak near 640 $\mathrm{nm}$ was observed in the absence of NRAS RNA. An increase in NRAS RNA concentration reduced the broad peak at $640 \mathrm{~nm}$ and concomitantly enhanced a new sharp peak at $680 \mathrm{~nm}$. The broad peak at $640 \mathrm{~nm}$ and the sharp peak at $680 \mathrm{~nm}$ are absorption patterns of an oligomeric phthalocyanine and monomeric phthalocyanine, respectively, in an aqueous solution ${ }^{36,40,42}$. Hence, the spectral change of ZnAPC induced by the addition of NRAS RNA shows that the oligomer of ZnAPC dissociates into the monomeric form by the binding to NRAS RNA. Figure $1 \mathrm{~b}$ shows $\triangle$ Absorbance (Abs. with RNA minus Abs. without RNA) of $2 \mu \mathrm{M}$ APCs at $680 \mathrm{~nm}$. The dissociation constant $\left(K_{\mathrm{d}}\right)$ of ZnAPC for binding to NRAS RNA was estimated to be $3.1 \mu \mathrm{M}$ at $25^{\circ} \mathrm{C}$ (see Materials and Methods for the procedure) (Fig. 1c). On the other hand, the absorbance spectrum of FeAPC was not altered by the addition of NRAS RNA (Fig. 1a, b), implying that FeAPC did not bind to NRAS RNA. Because the coordinated iron ion yields additional ligands at axial positions $s^{43,44}$, FeAPC stacking is offset, which probably inhibits the $\pi-\pi$ interaction between FeAPC and the G-quartet. Although further studies are necessary to elucidate why FeAPC does not bind to NRAS RNA, FeAPC may be useful as a control APC because of the low binding affinity for the target NRAS RNA. In the cases of both NiAPC and CuAPC, the higher NRAS RNA concentration enhanced a new sharp peak at $680 \mathrm{~nm}$ as shown in ZnAPC. In addition, a peak shift in the broad peak was observed, indicating that NRAS RNA is likely to promote the conversion from the oligomeric form into monomeric form of NiAPC and CuAPC via 
a

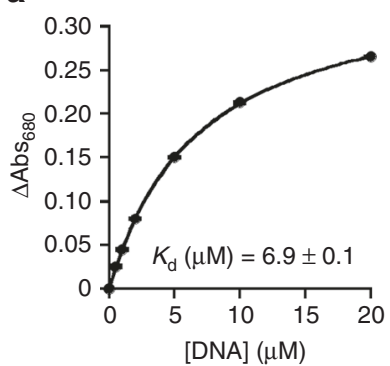

b

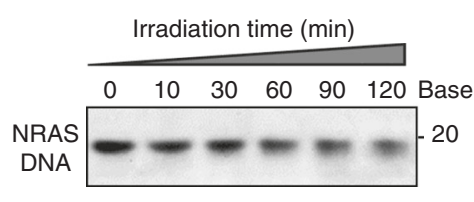

C

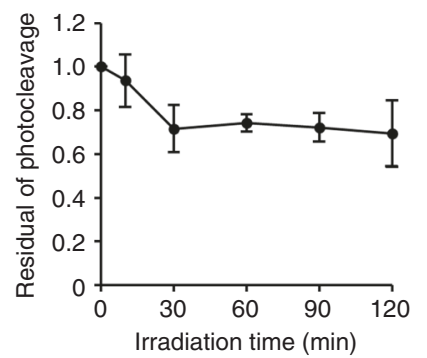

Fig. $4 \mathrm{ZnAPC}$ binds to NRAS DNA. a Plots of $\triangle$ Absorbance at $680 \mathrm{~nm}$ ( = absorbance with NRAS DNA minus absorbance without NRAS DNA) of $2 \mu \mathrm{M}$ $\mathrm{ZnAPC}$ with $0,0.5,1,2,5,10$ or $20 \mu \mathrm{M}$ NRAS DNA at $25^{\circ} \mathrm{C}$. Continuous lines are curve-fitting results with a theoretical equation, and the estimated $K_{d}$ of $\mathrm{ZnAPC}$ with NRAS DNA is also indicated. $\mathbf{b}$ Electrophoresis of $0.1 \mu \mathrm{M}$ NRAS DNA (in a $10 \%$ denaturing polyacrylamide gel) in the presence of $2 \mu \mathrm{M} Z \mathrm{ZAPC}$ after photo-irradiation for the indicated periods. c Residual intact DNA after the photo-cleavage. Error bars represent mean \pm SD; $n=3$

an intermediate form. The $K_{\mathrm{d}}$ values of NiAPC and CuAPC were estimated, with a two-state assumption as utilised for the $K_{\mathrm{d}}$ evaluation of $\mathrm{ZnAPC}$, to be 3.9 and $2.7 \mu \mathrm{M}$, respectively, at $25^{\circ} \mathrm{C}$ (Fig. 1c), indicating that the binding affinity of NiAPC and CuAPC for NRAS RNA is similar to that of ZnAPC.

Considering that RNA duplexes is abundant in cells, the APCs should bind to NRAS RNA in the presence of an excess of double-stranded RNA (dsRNA). We also checked the binding of APCs to a dsRNA (the nucleotide sequence is shown in Supplementary Table 1). Almost no absorbance change was observed for all the APCs after addition of dsRNA, suggesting that the APCs did not bind to dsRNA under these experimental conditions. Given that CuAPC and NiAPC did not bind to DNA duplexes $^{40}$, the APCs is assumed not to bind to DNA and RNA duplexes. It was next shown that the binding of $2 \mu \mathrm{M} \mathrm{ZnAPC}$ to NRAS RNA was almost the same even in the presence of $100 \mu \mathrm{M}$ dsRNA (ZnAPC spectrum, Fig. 1b). The value of $K_{\mathrm{d}}$ was $4.3 \mu \mathrm{M}$ at $25^{\circ} \mathrm{C}$, which is almost the same as the value in the absence of dsRNA. Taken together, these results support the possibility that ZnAPC, NiAPC and CuAPC, target the G-quadruplex derived from the $5^{\prime}$ UTR of NRAS mRNA in cells.

ZnAPC generates ROS after photo-irradiation. Phthalocyanines generate reactive oxygen species (ROS) after photo-irradiation, depending on the coordinated metal at the centre ${ }^{45-47}$. It is reasonable to hypothesise that the APCs used in this study generate ROS after photo-irradiation and effectively cleave the bound NRAS RNA. To determine whether the APCs can generate ROS in an aqueous solution, we utilised hydroxyphenyl fluorescein (HPF), which acts as a sensitive fluorescent probe for the detection of the most active ROS: the hydroxyl radical ${ }^{48}$. Fluorescence intensity of HPF at $515 \mathrm{~nm}$ increased after photo-irradiation of $\mathrm{ZnAPC}$ and $\mathrm{CuAPC}$, although the increment of the fluorescence intensity yielded by ZnAPC was significantly higher than that of CuAPC (Fig. 2a, b). Contrary to ZnAPC and CuAPC, fluorescence intensity of HPF was almost unchanged for FeAPC and NiAPC. These results indicated that ZnAPC effectively generates ROS upon photo-irradiation compared with other APCs.

We next examined the effects of ZnAPC, as well as FeAPC as a negative control APC, on the ROS formation in human breast cancer MCF-7 cells, in which NRAS amplification has been reported $^{49}$. Figure $2 c$ shows fluorescent images of HPF in MCF-7 cells in the absence of APC and in the presence of ZnAPC or FeAPC with or without photo-irradiation. Fluorescence from HPF was observed only in the presence of ZnAPC after photoirradiation, indicating that ROS formation by $\mathrm{ZnAPC}$ is significantly increased by the photo-irradiation. In addition, fluorescence intensities of HPF in the presence of FeAPC with or without photo-irradiation were much weaker than those in the presence of ZnAPC. These fluorescent intensities, conclusively listed in Fig. 2d, show that the fluorescence intensity yielded by ZnAPC with photo-irradiation is significantly higher than that in the other cases. Moreover, measurement of cell viability by trypan blue exclusion-based cell staining revealed that ZnAPC markedly decreased cell viability after photo-irradiation (Fig. $2 \mathrm{e}$ and Supplementary Figure 2), whereas other conditions did not influence cell viability. These results suggested that ZnAPC generates ROS upon photo-irradiation and concomitantly induces cell death.

ZnAPC photo-cleaves a G-quadruplex derived from NRAS mRNA. From this point of view, we tested whether, upon photoirradiation, ZnAPC degraded the NRAS RNA under the experimental conditions. Figure 3a presents denaturing polyacrylamide gel electrophoresis of NRAS RNA and dsRNA in the presence of APCs after various irradiation periods from 0 to $120 \mathrm{~min}$. Only in the case of NRAS RNA in the presence of ZnAPC, upon photoirradiation, did band intensity of the intact NRAS RNA decrease (Fig. 3a), and the cleaved NRAS RNA was detected (see Supplementary Figure $3 a$ and $b$ for the whole image of the gel and the cleaved product). On the other hand, reduction of the band intensity of dsRNA was not observed, in agreement with the properties of $\mathrm{ZnAPC}$ binding to dsRNA. Figure $3 \mathrm{~b}$ shows relative residual amounts of RNAs after photo-irradiation-induced cleavage. The residual amount of NRAS RNA was significantly decreased during the photo-irradiation of ZnAPC to the value lower than 0.4 , showing that more than $60 \%$ of NRAS RNA was cleaved after the photo-irradiation for $120 \mathrm{~min}$. Furthermore, it was found that other anionic phthalocyanines, i.e. FeAPC, NiAPC and CuAPC, did not cleave NRAS RNA after photo-irradiation.

We next tested whether ZnAPC cleaved RNA oligonucleotides derived from the full sequence of the 5' UTR of NRAS mRNA harbouring the G-quadruplex motif (NRAS F-RNA) (Supplementary Figure $4 \mathrm{a}$ and b). The synthesised DIG-labelled NRAS F-RNA by in vitro transcription was used after purification. As shown in the model sequence, NRAS RNA, the band intensity of NRAS F-RNA diminished after photo-irradiation (Fig. 3c). In addition, the products of photo-cleavage of NRAS FRNA were clearly observed (Supplementary Figure 4c). These results indicate that NRAS F-RNA can be photo-cleaved by ZnAPC.

The results on the binding, on the ROS generation, and the photo-cleavage abilities indicate that $\mathrm{ZnAPC}$ is a promising photosensitiser targeting NRAS mRNA in living cells. Moreover, 
a

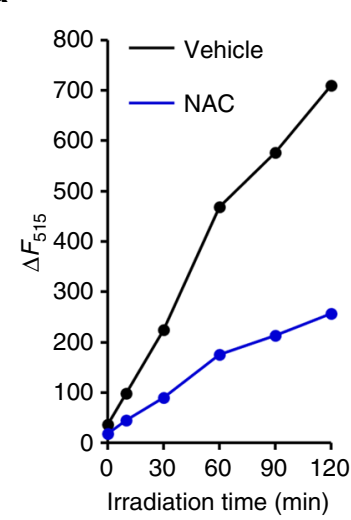

d

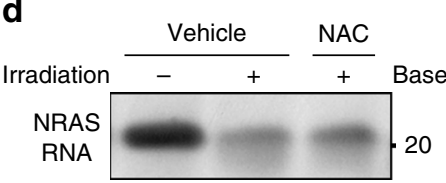

e

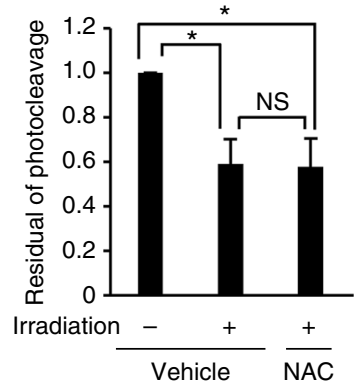

b

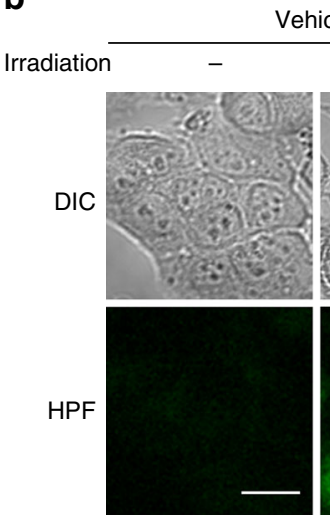

f

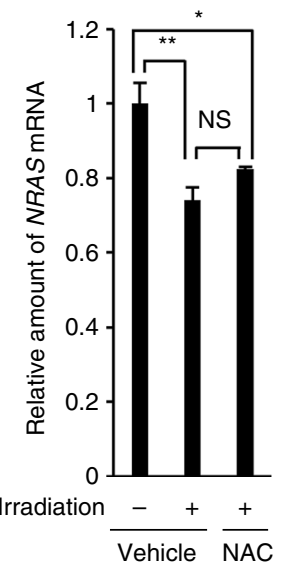

C

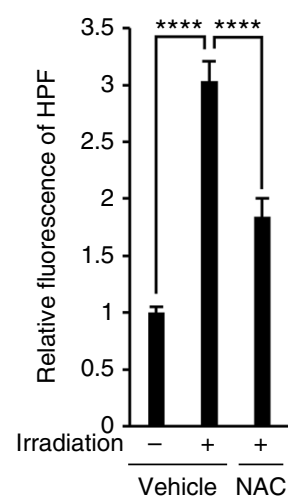

h

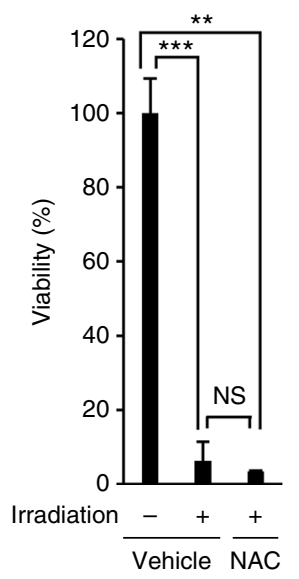

Fig. 5 NAC does not inhibit downregulation of NRAS expression by ZnAPC. a Fluorescence spectra of $10 \mu \mathrm{M}$ HPF in the presence of $10 \mathrm{mM}$ NAC with $2 \mu \mathrm{M}$ $\mathrm{ZnAPC}$ after photo-irradiation were acquired at $25^{\circ} \mathrm{C}$. Fluorescence intensities of HPF at $515 \mathrm{~nm}$ after photo-irradiation (0-120 min) are shown. $\mathbf{b}$, c Cells pre-treated with $10 \mu \mathrm{M} \mathrm{HPF}$ together with $10 \mathrm{mM} \mathrm{NAC}$ for 30 min were treated with $10 \mu \mathrm{M}$ ZnAPC for 30 min and subsequently photo-irradiated for $1 \mathrm{~h}$. DIC images of cells and fluorescent images of HPF are presented in $\mathbf{b}$. Scale bar, $20 \mu \mathrm{m}$. The mean fluorescence intensity of HPF was quantified. c Relative fluorescence intensities are shown, and each bar represents mean \pm SD of 10 images. $\mathbf{d}$ Electrophoresis (in a $10 \%$ denaturing polyacrylamide gel) of $0.1 \mu \mathrm{M}$ NRAS RNA in the presence of $2 \mu \mathrm{M}$ ZnAPC with or without $10 \mathrm{mM} \mathrm{NAC}$, followed by photo-irradiation for $2 \mathrm{~h}$. e Residual intact RNA after the photocleavage of NRAS RNA. Each bar represents mean $\pm \mathrm{SD} ; \mathrm{n}=3$. f, $\mathbf{g}$ Cells pre-treated with $10 \mu \mathrm{M}$ ZnAPC together with $1 \mu \mathrm{g} \mathrm{ml} \mathrm{l}^{-1}$ actinomycin $\mathrm{D}$ and $10 \mathrm{mM}$ NAC for $1 \mathrm{~h}$ were photo-irradiated for $2 \mathrm{~h}$. $\mathbf{f}$ The amount of NRAS mRNA was evaluated by real-time PCR. Each bar represents mean \pm SD; $n=3$. $\mathbf{g}$ The cells were incubated for $5 \mathrm{~h}$ after photo-irradiation. The cell extracts were subjected to immunoblot analysis with antibodies against NRAS; $\beta$-actin served as a loading control. Blots of NRAS and $\beta$-actin were quantified, and the relative values of NRAS are shown. $\mathbf{h}$ Cells pre-treated with $10 \mu \mathrm{M}$ ZnAPC together with $10 \mathrm{mM} \mathrm{NAC}$ for $1 \mathrm{~h}$ were incubated for $24 \mathrm{~h}$ after photo-irradiation for $2 \mathrm{~h}$. The number of viable cells was determined by Trypan Blue exclusion-based cell staining. The number of treated cells was normalised to that of untreated cells. Each bar represents mean $\pm S D ; n=3$. For statistical significance, an unpaired $t$-test was performed. ${ }^{\star} p<0.01 ;{ }^{\star \star} p<0.001 ;{ }^{\star \star \star} p<0.0001 ;{ }^{\star \star \star \star} p<0.00001$; NS not significant, $p>0.05$

we found that $\mathrm{ZnAPC}$ is capable of cell penetration and diffused throughout the cytosol in MCF-7 cells (Supplementary Figure 5). On the basis of ZnAPC, we next attempted to confirm that ZnAPC targets the G-quadruplex in the $5^{\prime}$ UTR of NRAS mRNA in living cells. Figure $3 \mathrm{~d}$ shows a relative amount of NRAS mRNA in the absence and in the presence of ZnAPC or FeAPC with or without photo-irradiation. Treatment with ZnAPC did not influence the relative amount of NRAS mRNA without photoirradiation. On the other hand, it was found that the $120 \mathrm{~min}$ photo-irradiation reduced it by $\sim 35 \%$. As expected, treatment with FeAPC had no influence on the amount of NRAS mRNA even after photo-irradiation. The specific reduction in the amount of NRAS mRNA by the combination of ZnAPC and photoirradiation is in agreement with the photo-cleavage of NRAS RNA and NRAS F-RNA by ZnAPC as mentioned above. We next determined the expression level of the NRAS protein after the same treatments (Fig. 3e). The photo-irradiation in the absence of
ZnAPC did not reduce NRAS protein expression as shown in lane 2. In contrast, the expression level was significantly decreased by photo-irradiation in the presence of ZnAPC, up to the value of 0.38 (lane 4), but not in the presence of FeAPC (lane 6). These findings are consistent with the mRNA expression levels under the same conditions (Fig. 3d).

It has been reported that formation of a G-quadruplex in the $5^{\prime}$ UTR of NRAS mRNA impairs its translation ${ }^{21}$. Given that the expression of NRAS was not significantly downregulated by ZnAPC without photo-irradiation, $\mathrm{ZnAPC}$ is unlikely to promote stabilisation of the G-quadruplex in the 5' UTR of NRAS mRNA in the cell. On the other hand, NRAS expression was decreased by ZnAPC after photo-irradiation, implying that ZnAPC bound and irreversibly photo-cleaved the G-quadruplex of NRAS mRNA in the cell.

Furthermore, we tested whether ZnAPC bound the Gquadruplexes of not only NRAS mRNA but also of corresponding 
a

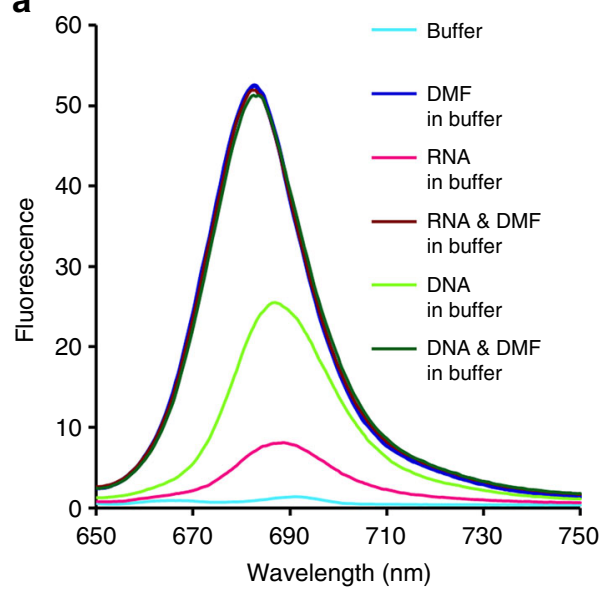

b

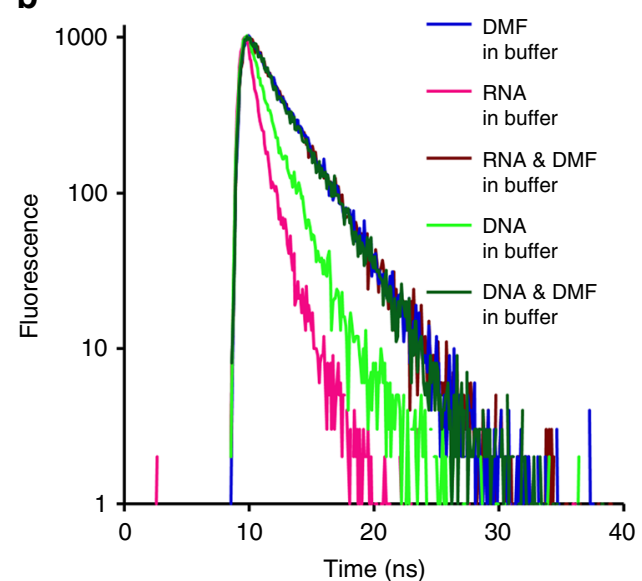

C

\begin{tabular}{cccccc}
\hline Oligo-type & - & RNA & RNA & DNA & DNA \\
DMF & + & - & + & - & + \\
\hline$\tau_{1}(\mathrm{~ns})$ & 2.97 & 0.35 & 2.94 & 0.53 & 2.94 \\
$\tau_{2}(\mathrm{~ns})$ & & 1.23 & & 1.94 & \\
$\tau_{\text {total }}(\mathrm{ns})$ & 2.97 & 0.92 & 2.94 & 1.63 & 2.94 \\
\hline
\end{tabular}

Fig. 6 Energy transfer from ZnAPC to NRAS RNA is greater than that to NRAS DNA. a Fluorescence spectra of $2 \mu \mathrm{M} Z n A P C$ under the following experimental conditions: in the absence of NRAS RNA in the buffer (right blue) and in the buffer containing 30 wt\% DMF (dark blue), in the presence of NRAS RNA in the buffer (red) and in a buffer containing $30 \mathrm{wt} \%$ DMF (brown), in the presence of NRAS DNA in the buffer (light green), and in the buffer containing $30 \mathrm{wt} \% \mathrm{DMF}$ (dark green). b Fluorescence decay of ZnAPC under the experimental conditions listed in $\mathbf{a}$. Fluorescence decay in the buffer is not shown because of the insufficient fluorescence intensity. All the experiments were conducted with $2 \mu M$ ZnAPC, $10 \mu M$ NRAS RNA, and $10 \mu \mathrm{M}$ NRAS DNA. c Fluorescence lifetime, $\tau$, was evaluated with a theoretical equation of single or double exponential decay for the fluorescence decay obtained in $\mathbf{b}$

DNA (NRAS DNA, the nucleotide sequence is shown in Supplementary Table 1). Figure $4 \mathrm{a}$ shows $\Delta \mathrm{Abs}$ at $680 \mathrm{~nm}$ of 2 $\mu \mathrm{M}$ ZnAPC vs. NRAS DNA concentration in a titration experiment. It was found that the addition of NRAS DNA monomerised $\mathrm{ZnAPC}$, and $K_{\mathrm{d}}$ was evaluated and found to be 6.9 $\mu \mathrm{M}$ at $25^{\circ} \mathrm{C}$. The affinity of ZnAPC for NRAS DNA was of the same order of magnitude as that of NRAS RNA. It is noteworthy, however, that the degradation of NRAS DNA by ZnAPC was only $\sim 30 \%$ after the 120 min photo-irradiation (Fig. $4 \mathrm{~b}$, c), whereas the degradation of NRAS RNA was $\sim 70 \%$ as shown above (Fig. 3a, b). These results suggested that there is a specific mechanism of photo-cleavage of NRAS RNA.

ZnAPC directly transfers electrons to NRAS RNA. To elucidate the possible mechanism of cleavage of RNAS RNA by ZnAPC, we tested whether a ROS scavenger, $N$-acetyl cysteine (NAC), influences the photo-cleavage by NRAS RNA. Figure $5 \mathrm{a}$ shows a fluorescence intensity change of $10 \mu \mathrm{M}$ HPF in the presence and absence of $10 \mu \mathrm{M}$ NAC. It was confirmed that NAC decreased the fluorescence of HPF, corresponding to ROS production by ZnAPC with photo-irradiation. As shown in the test tube, NAC also reduced ROS production in the cell (Fig. 5b, c). NAC's effects on the photo-cleavage efficacy were further studied in the test tube and in the cell. In contrast to the ROS reduction, it was found by electrophoresis after the photo-irradiation that NAC did not affect photo-cleavage of NRAS RNA by ZnAPC (Fig. 5d, e). Furthermore, we demonstrated that NAC did not attenuate the downregulation of NRAS mRNA and NRAS protein expression by ZnAPC (Fig. 5f, g). Therefore, both in the test tube and in the cell, NAC reduces the ROS formation but does not inhibit the photo-cleavage. It was also found that NAC did not suppress the cell death induced by ZnAPC after photo-irradiation (Fig. 5h). These results suggest that ZnAPC induces cell death via downregulation of NRAS regardless of ROS generation. Therefore, other factors, besides ROS production, are involved in the photo-cleavage of NRAS RNA and in the downregulation of NRAS by ZnAPC with photo-irradiation.

We therefore investigated by fluorescence lifetime measurement how ZnAPC cleaves the G-quadruplex of NRAS RNA. ZnAPC emits fluorescence when it is in the monomeric form ${ }^{50,51}$ In agreement with these previous reports, we found here that ZnAPC emitted a distinct fluorescent signal after the monomerisation and binding to NRAS RNA in the buffer, whereas fluorescence intensity was negligible without NRAS RNA (Fig. 6a). Fluorescence intensity of ZnAPC was also observed in a mixed solution (the buffer containing $30 \mathrm{wt} \%$ dimethylformamide $[\mathrm{DMF}])$, in which ZnAPC is highly soluble and exists as a monomer (the absorption spectrum is given in Supplementary Figure 6). In the mixed solution, fluorescence intensities of ZnAPC in the presence of NRAS RNA or NRAS DNA were identical to that in the absence of the G-quadruplex. These fluorescence intensities were greater than those in the buffer, indicating that the mixed solution accelerated ZnAPC monomerisation. Figure $6 \mathrm{~b}$ illustrates fluorescence decay of ZnAPC under these conditions. The fluorescence decay of $\mathrm{ZnAPC}$ without the G-quadruplex in the mixed solution could be fitted to a theoretical equation of a single exponential function, and fluorescence lifetime, $\tau_{1}\left(=\tau_{\text {total }}\right)$, was estimated to be $2.97 \mathrm{~ns}$. The $\tau_{1}$ values in the presence of NRAS RNA or NRAS DNA were the same as those without the G-quadruplex and consistent with the steady-state fluorescence spectra (Fig. 6a). It has been reported that fluorescence decay of $\mathrm{Zn}$-phthalocyanine derivatives in DMF follows a single exponential function and that their 
$\tau_{\text {total }}$ values are evaluated to be 1 to $4 \mathrm{~ns}$, which correspond to the conversion from $\mathrm{S}_{1}$ to $\mathrm{S}_{0}{ }^{52-54}$. Thus, the $\tau_{\text {total }}$ values listed in Fig. $6 c$ for the mixed solution are consistent with the other reports. Moreover, the fluorescence decay in the buffer in the presence of NRAS RNA could be fitted to a double exponential function but not to a single one. $\tau_{1}$ and $\tau_{2}$ were estimated to be 0.35 and $1.23 \mathrm{~ns}$, respectively (Fig. $6 \mathrm{c}$ ). The value of $\tau_{\text {total }}$ was 0.92 ns. Similarly, $\tau_{1}$ and $\tau_{2}$ were 0.53 and $1.94 \mathrm{~ns}$ for the double exponential function and the buffer with NRAS DNA. Because larger dipole moments of coexisting molecules can increase the energy transfer efficiency, fluorescence lifetime is generally shorter in a more polar environment. The value of $\tau_{\text {total }}$ in the presence of NRAS RNA was smaller than that with NRAS DNA, suggesting that smaller $K_{\mathrm{d}}$ makes fluorescence lifetime shorter. Therefore, it is possible that $\pi-\pi$ stacking interactions with a large aromatic G-quartet led to a less polar environment of ZnAPC.

It has been reported that fluorescence decay of a porphyrin-DNA G-quadruplex complex has two lifetime components, whereas the porphyrin has a single lifetime component in its free state ${ }^{55}$. In that study, the authors concluded that two lifetime components indicate the existence of two binding states of the porphyrin because they also found that the binding stoichiometry of the porphyrin and DNA G-quadruplex is 2:1. In contrast to that porphyrin, it has been shown that the stoichiometry of CuAPC with a DNA G-quadruplex is $1: 1^{36}$. Thus, a single binding mode of ZnAPC is not consistent with a possible mechanism involving two fluorescence lifetime components. Notably, it has been demonstrated that guanine mononucleotide and guanine-containing polynucleotides decrease fluorescence lifetime of a porphyrin ${ }^{56-58}$. This finding was interpreted as a manifestation of photo-induced electron transfer between the guanine base and the photoexcited porphyrin. In addition, the decrease in a fluorophore activity under the influence of photo-induced electron transfer was recently applied to monitoring a structure switch from a hairpin duplex to a Gquadruplex by measurement of the fluorescence reduction and thus shorter fluorescence lifetime ${ }^{59}$. According to those results, it is possible that the sub-nano-second $\tau_{1}$ values $(0.35 \mathrm{~ns}$ for NRAS RNA and $0.53 \mathrm{~ns}$ for NRAS DNA) reflect the photo-induced electron transfer that directly proceeds between ZnAPC and a Gquadruplex.

It has been reported that $\mathrm{H}$ (hydrogen) abstraction from an RNA strand by the hydroxyl radical is much faster than the reaction with a hydroxyl radical scavenger, and consequently such a scavenger cannot inhibit the $\mathrm{H}$ abstraction from $\mathrm{RNA}^{60}$. It is therefore possible that $\tau_{1}$ of NRAS RNA, smaller than that of NRAS DNA (Fig. 6b, c), supports the direct energy transfer from ZnAPC to NRAS RNA rather than to NRAS DNA. Given that cleavage of NRAS RNA via photo-irradiation of ZnAPC is more effective than that of NRAS DNA (Figs. $3 a, b$ and $4 b, c$ ), the direct energy transfer is likely to cause its photo-cleavage. Therefore, the longer and shorter fluorescence lifetimes of $\mathrm{ZnAPC}$ in the presence of the G-quadruplex can be attributed to the conversion from $S_{1}$ to $S_{0}$ and the photo-induced electron transfer, respectively. The photo-irradiation of NRAS RNA by photoinduced electron transfer via $\mathrm{H}$ abstraction from the RNA strand enables ZnAPC to selectively cleave the RNA G-quadruplex but not other biomolecules present in the vicinity of ZnAPC. The cleavage mechanism will be further discussed below along with photo-cleavage reactions under aerobic and anaerobic conditions.

\section{Discussion}

Our findings presented in this study highlight the direct photocleavage of the G-quadruplex in NRAS mRNA by ZnAPC. On the other hand, it was also clearly shown that not all RNA
G-quadruplexes are targeted by $\mathrm{ZnAPC}$. To rationalise the selectivity of ZnAPC, we studied ZnAPC binding with various RNA G-quadruplexes. First, we evaluated the binding of ZnAPC to other naturally occurring G-quadruplex-forming RNA oligonucleotides (VEGF RNA and BCL2 RNA) derived from the $5^{\prime}$ UTR of mRNA encoding vascular endothelial growth factor (VEGF) and B-cell lymphoma 2 (Bcl2), respectively. Nucleotide sequences and CD spectra of these RNAs are given in Supplementary Table 1 and Supplementary Figure 1, respectively. Supplementary Figure $7 \mathrm{a}$ shows VIS absorption spectra of $2 \mu \mathrm{M}$ ZnAPC in the presence of various concentrations of VEGF RNA or BCL2 RNA, respectively. The smaller increase in absorbance at $680 \mathrm{~nm}$ showed that VEGF RNA and BCL2 RNA produced lesser amounts of monomeric ZnAPC as compared with NRAS RNA (Supplementary Figure $7 \mathrm{~b}$ ). The values of $K_{\mathrm{d}}$ were estimated to be $48 \mu \mathrm{M}$ for VEGF RNA and $36 \mu \mathrm{M}$ for BCL2 RNA at $25^{\circ} \mathrm{C}$. These results mean that the binding of ZnAPC to VEGF RNA or BCL2 RNA is weaker than the binding to NRAS RNA $\left(K_{\mathrm{d}}=3.1 \mu \mathrm{M}\right.$ at $25^{\circ} \mathrm{C}$, as shown in Fig. 1c). Similarly, fluorescence intensity changes of ZnAPC promoted by VEGF RNA and BCL2 RNA were smaller than the change driven by NRAS RNA (Supplementary Figure 7c). In addition to the titration experiments traced by a VIS absorbance change, $K_{\mathrm{d}}$ values of ZnAPC with these RNAs were evaluated with more data points in a lower concentration range because sensitivity of fluorescence detection is much higher than that of absorbance change. Supplementary Figure $7 \mathrm{~d}$ depicts the titration curves traced by the fluorescence and absorbance changes, revealing that the titration curves are almost identical to each other. The values of $K_{\mathrm{d}}$ estimated based on these independent titration data were also very similar to each other (Supplementary Figure 7e). These results suggest that the monomerisation of ZnAPC and fluorescence enhancement, reflecting electron and energy transfers, correlate with each other. Furthermore, it was found that the photo-cleavage activity of ZnAPC towards VEGF RNA and BCL2 RNA is undetectable (Supplementary Figure 7f, g).

We wondered how the number of G-quartets and the nucleotide sequence in the loop regions affect the binding of ZnAPC to RNA G-quadruplexes. To address this point, we systematically designed several NRAS RNA mutants (NRAS MT1 RNA to NRAS MT5 RNA: nucleotide sequences are shown in Supplementary Table 1). Firstly, it was confirmed that all the RNAs formed a parallel G-quadruplex same as NRAS RNA (CD spectra are presented in Supplementary Figure 1). NRAS RNA has three G-quartet planes and relatively short loop regions, whereas VEGF RNA and BCL2 RNA have two G-quartet planes and longer loop regions, respectively. Based on these differences, NRAS MT1 RNA and NRAS MT2 RNA were designed to have the same loop sequences as do VEGF RNA and BCL2 RNA, respectively. The $K_{\mathrm{d}}$ values of ZnAPC for NRAS MT1 RNA and NRAS MT2 RNA, evaluated by the VIS absorbance changes, were estimated to be 9.2 and $4.2 \mu \mathrm{M}$, respectively, at $25^{\circ} \mathrm{C}$ (Supplementary Figure 8 ). These values are comparable to that of NRAS RNA (3.1 $\mu \mathrm{M}$, as shown in Fig. 1c), implying that high affinity of ZnAPC for NRAS RNA is not dependent on the loop sequences. NRAS MT3 RNA maintains the loop sequence but consists of only two G-quartet planes. $K_{\mathrm{d}}$ was estimated to be $48 \mu \mathrm{M}$ at $25^{\circ} \mathrm{C}$ (Supplementary Figure 8c), which is more than 10 -fold greater than that of NRAS RNA. This finding shows that ZnAPC preferentially binds the G-quadruplex consisting of three rather than two G-quartets. Although the G-quadruplex structure of BCL2 RNA consists of three G-quartet planes, the binding affinity for $\mathrm{ZnAPC}$ is low. Because the number of guanines at the $5^{\prime}$ and $3^{\prime}$ ends of BCL2 RNA was greater than that of NRAS RNA, we next examined the binding for NRAS MT4 RNA and NRAS MT5 RNA, which have one more guanine nucleotide and uridine 
nucleotide at both ends of NRAS RNA, respectively. The $K_{\mathrm{d}}$ values of ZnAPC with NRAS MT4 RNA and NRAS MT5 RNA at $25^{\circ} \mathrm{C}$ were estimated to be 95 and $4 \mu \mathrm{M}$, respectively, revealing that the additional guanine nucleotides but not uridine nucleotides significantly decreased the affinity for ZnAPC. Considering that the sequence of NRAS MT5 RNA is derived from NRAS mRNA (refer to the sequence depicted in Supplementary Figure $4 \mathrm{~b}$ ), not only three G-quartets but also the nucleotides next to the G-quadruplex-forming region may be important for strong affinity for ZnAPC. Although further studies are required, these results suggest that the number of G-quartet planes and the flanking sequences at the $5^{\prime}$ and $3^{\prime}$ ends contribute to the sequence-selective binding and photo-cleavage of target NRAS RNA and NRAS mRNA by ZnAPC.

It is known that hypoxia, a common characteristic of malignant tumours, promotes invasion and metastasis of cancer cells and often causes resistance to chemotherapy and radiotherapy, and this resistance is mediated by hypoxia-inducible factors (HIFs) ${ }^{61,62}$. Given that RAS induces HIF-1a expression, small molecules targeting RAS during hypoxia will be effective as therapeutic agents against cancer. Here, we found that ZnAPC photo-cleaves the G-quadruplex in NRAS mRNA even in the presence of NAC, an ROS scavenger (Fig. $5 \mathrm{~d}-\mathrm{g}$ ). It was therefore expected that the photo-cleavage activity of ZnAPC for the RNA G-quadruplex can be attained even under anaerobic conditions. To test this notion, we compared the photo-cleavage efficiency under aerobic and anaerobic conditions. It was demonstrated that the photo-cleavage by ZnAPC under the anaerobic conditions was comparable with that under the aerobic conditions (Supplementary Figure 9). Because oxygen molecules are required for ROS generation, this photo-cleavage in the anaerobic condition suggests that the photo-induced direct energy transfer from ZnAPC to NRAS RNA plays a critical role in the photo-cleavage reaction. Taken together, these results indicate that $\mathrm{ZnAPC}$ is expected to suppress aggressive phenotypes of cancer cells via downregulation of RAS signalling pathways even when cancer cells not only are resistant to ROS but also are under hypoxic conditions.

In conclusion, we show here that NRAS expression can be downregulated through targeting the G-quadruplex in NRAS mRNA by ZnAPC. Studies using both melanoma cells and melanoma tumour-bearing mice by the group of Luigi Xodo have successfully shown that porphyrin $\mathrm{C} 14 \mathrm{H} 28$-alkyl derivative $\mathrm{C} 14$, a photosensitiser identified as a G-quadruplex binding compound, induces growth arrest of cancer cells through downregulation of KRAS by targeting the G-quadruplex in its mRNA $^{10,11}$. In these articles, it was shown that C14 inhibits translation of KRAS mRNA even without photo-irradiation and induces light-mediated cleavage of KRAS mRNA, which is thought to be associated with its ability to generate ROS. By combining these results on KRAS and our results on NRAS in this study, we can propose that the specific binding and photocleavage of G-quadruplex structures of RAS mRNAs by RNA Gquadruplex ligands are promising as photosensitisers in a molecularly targeted PDT for downregulation of a RAS signalling pathway.

\footnotetext{
Methods

Materials and antibodies. All the high-pressure liquid chromatography (HPLC)grade DNA and RNA oligonucleotides analysed in this study were acquired from Hokkaido System Science Co., Ltd. and Sigma-Aldrich Japan and used without further purification. Single strand concentrations of the oligonucleotides were determined by measuring the absorbance at $260 \mathrm{~nm}$ and high temperature using a UV-1800 spectrometer (Shimadzu, Kyoto, Japan). Single-strand extinction coefficients were calculated from mononucleotide and dinucleotide data using the nearest-neighbor approximation ${ }^{63}$. ZnAPC [zinc(II) phthalocyanine $3,4^{\prime}, 4^{\prime \prime}$, $4^{\prime \prime \prime}$-tetrasulfonic acid, tetrasodium salt] was purchased from Frontier Scientific,
}

FeAPC [iron(III) phthalocyanine- $4,4^{\prime}, 4^{\prime \prime}, 4^{\prime \prime \prime}$-tetrasulfonic acid, monosodium salt, compound with oxygen, hydrate], NiAPC [nickel(II) phthalocyanine-tetrasulfonic acid tetrasodium salt] and CuAPC [copper(II) phthalocyanine-3, $4^{\prime}, 4^{\prime \prime}, 4^{\prime \prime \prime}$-tetrasulfonic acid, tetrasodium salt] were purchased from Sigma-Aldrich. Actinomycin $\mathrm{D}$ and NAC were bought from WAKO Pure Chemical Industries, Ltd. Hydroxyphenyl fluorescein (HPF) was purchased from Goryo Kayaku Co., Ltd. Anti-N Ras mouse monoclonal (Santa Cruz Biotechnology, sc-31; $1: 100$ ) and anti- $\beta$-actin (Sigma-Aldrich, A1978; 1:1000) mouse monoclonal antibodies served as a primary antibody. A horseradish peroxidase (HRP)-conjugated sheep anti-mouse IgG antibody (Amersham Pharmacia, NXA931V; 1:10,000) served as a secondary antibody.

Absorption spectroscopy. Visible (Vis) absorption spectra for ZnAPC $(2 \mu \mathrm{M})$ and FeAPC $(2 \mu \mathrm{M})$ were recorded on a spectrophotometer (UV-1800; Shimadzu, Kyoto, Japan) with a quartz cell with $1 \mathrm{~cm}$ path length. All the measurements were carried out in a buffer consisting of $50 \mathrm{mM} 2-(\mathrm{N}$-morpholino) ethanesulfonate [MES]- $\mathrm{LiOH}(\mathrm{pH} 7)$ and $100 \mathrm{mM} \mathrm{KCl}$ at $25^{\circ} \mathrm{C}$. Before measurement, each sample was heated to $90^{\circ} \mathrm{C}$ for $5 \mathrm{~min}$ and gently cooled to $25^{\circ} \mathrm{C}$ at $0.5^{\circ} \mathrm{C} \mathrm{min}{ }^{-1}$.

Fluorescence spectroscopy. Fluorescence spectra for $2 \mu \mathrm{M} \mathrm{ZnAPC}$ in the presence of $0-20 \mu \mathrm{M}$ RNA in a buffer consisting of $50 \mathrm{mM}$ MES-LiOH $(\mathrm{pH} 7)$ and $100 \mathrm{mM} \mathrm{KCl}$ (ex: $620 \mathrm{~nm}$, em: 650-750 nm) were recorded on a FP-8200 spectrofluorometer (JASCO, Tokyo, Japan) equipped a temperature controller with a $0.3 \mathrm{~cm} \times 0.3 \mathrm{~cm}$ quartz cell at $25^{\circ} \mathrm{C}$. Before measurement, each sample was heated to $90^{\circ} \mathrm{C}$ for $5 \mathrm{~min}$ and gently cooled to $25^{\circ} \mathrm{C}$ at $0.5^{\circ} \mathrm{C} \mathrm{min}^{-1}$.

Photo-irradiation. For photo-irradiation of phthalocyanines in vitro, ZnAPC, FeAPC, NiAPC or CuAPC in a buffer consisting of $50 \mathrm{mM}$ MES-LiOH (pH 7) and $100 \mathrm{mM} \mathrm{KCl}$ was irradiated with a light-emitting diode (LED) light with peak emission wavelength of $615 \mathrm{~nm}$ (PFBR-150RD-MN; $141.1 \mathrm{~J} \mathrm{~cm}^{-2}$, CCS Inc., Kyoto, Japan). For photo-irradiation of phthalocyanines in the cell, cells were seeded at $5 \times 10^{4}$ cells $\mathrm{cm}^{-2}$ and cultured overnight. The medium was then replaced with a $\mathrm{CO}_{2}$-independent medium (Gibco) supplemented with $10 \%$ of foetal bovine serum and $1 \%$ of the penicillin/streptomycin solution. The cells were pre-treated with $\mathrm{ZnAPC}$ or FeAPC for $30 \mathrm{~min}$ or $1 \mathrm{~h}$ at $37^{\circ} \mathrm{C}$ and next irradiated with LED light with peak emission wavelength of $630 \mathrm{~nm}$ (TH-160 $\times 120 \mathrm{RD} ; 5.5 \mathrm{~J} \mathrm{~cm}^{-2}$, CCS Inc., Kyoto, Japan).

Evaluation of ROS formation. An in vitro assay of ROS formation after the photoirradiation of the APCs, fluorescence for $10 \mu \mathrm{M}$ HPF in the presence of $2 \mu \mathrm{M}$ ZnAPC, FeAPC, NiAPC or CuAPC in a buffer consisting of $50 \mathrm{mM}$ MES-LiOH (pH 7) and $100 \mathrm{mM} \mathrm{KCl}$ was recorded at $25^{\circ} \mathrm{C}$ (ex: $490 \mathrm{~nm}$, em: $500-700 \mathrm{~nm}$ ); an FP-8200 spectrofluorometer (JASCO, Tokyo, Japan) connected to a temperature controller was used with a quartz cell with $0.3 \mathrm{~cm}$ path length. Before measurement, each sample was heated to $90^{\circ} \mathrm{C}$ for $5 \mathrm{~min}$ and gently cooled to $25^{\circ} \mathrm{C}$ at $0.5^{\circ} \mathrm{C} \mathrm{min}-1$. To evaluate the ROS formation in the cell, cells cultured on $35 \mathrm{~mm}$ glass bottom dishes (Matsunami Glass Ind., Ltd.) were pre-treated with ZnAPC or FeAPC for $30 \mathrm{~min}$, followed by $10 \mu \mathrm{M}$ HPF for $30 \mathrm{~min}$. After photo-irradiation for $60 \mathrm{~min}$, the cells were washed with PBS. A $488 \mathrm{~nm}$ laser was employed for imaging. Images were acquired by means of a confocal microscope (LSM700; Zeiss, Tokyo, Japan). The mean fluorescence intensity of HPF was quantified in the ImageJ software.

Cleavage of RNA and DNA oligonucleotides. The mixtures of $2 \mu \mathrm{M}$ ZnAPC or FeAPC and $0.1 \mu \mathrm{M}$ RNA or DNA in a buffer consisting of $50 \mathrm{mM}$ MES-LiOH (pH 7) and $100 \mathrm{mM} \mathrm{KCl}$ were heated to $90^{\circ} \mathrm{C}$ for $5 \mathrm{~min}$ and gently cooled to $25^{\circ} \mathrm{C}$ at $0.5^{\circ} \mathrm{C} \mathrm{min}{ }^{-1}$. After the photo-irradiation of the mixtures in a quartz cell with 0.1 $\mathrm{cm}$ path length, a 1.5 -fold volume of a stop solution ( $80 \mathrm{wt} \%$ formamide, $10 \mathrm{mM}$ $\mathrm{Na}_{2}$ EDTA, and $0.01 \%$ blue dextran) was added. The samples containing $0.6 \mathrm{pmol}$ RNA or DNA were then analysed by electrophoresis in a 10 or $15 \%$ polyacrylamide gel with $7 \mathrm{M}$ urea at $70^{\circ} \mathrm{C}$. After that, the gels were stained with SYBR ${ }^{\circledast}$ Gold (Invitrogen), and the signals were quantified with a fluorescent imager, Typhoon FLA-9500 (GE Healthcare, Tokyo, Japan). When the efficiency of RNA cleavage was compared with that under aerobic and anaerobic conditions, the mixture of 2 $\mu \mathrm{M} \mathrm{ZnAPC}$ and $0.1 \mu \mathrm{M}$ NRAS RNA was dried before we dissolved it in the buffer.

To conduct the reaction under anaerobic conditions, the buffer was purged with argon for $5 \mathrm{~min}$ and then frozen by means of liquid $\mathrm{N}_{2}$ followed by decompressing and purging with Ar gas three times. After thawing, the mixtures were dissolved in the buffer in the argon-equilibrated glove box. Uncropped scans of gels are shown in Supplementary Figure 10.

Cleavage of NRAS F-RNA. The pUC57 NRAS F-RNA vector containing the sequence encoding the $5^{\prime}$ UTR of NRAS mRNA following T7-promoter was constructed (GenScript Japan Inc.). The vector was digested with EcoRV, and the resultant DNA fragments were next separated by electrophoresis in a $1 \%$ agarose gel. The fragment containing DNA encoding the $5^{\prime}$ UTR of NRAS mRNA was purified by ethanol precipitation after it was extracted from the agarose gel with the GenElute $^{\mathrm{TM}}$ Gel Extraction Kit (Sigma-Aldrich). This DNA served as a template 
for in vitro RNA transcription. RNA was labelled with DIG and detected using the DIG RNA Labelling Kit (Roche Biochemicals). Briefly, the transcription reaction driven by T7 RNA polymerase in a reaction mixture containing DIG-11-UTG and an RNase inhibitor was carried out at $42^{\circ} \mathrm{C}$ for $1 \mathrm{~h}$. After treatment with DNase I at $37^{\circ} \mathrm{C}$ for $15 \mathrm{~min}$, RNA was purified by ethanol precipitation after phenol/chloroform extraction. A 1.5-fold volume of a stop solution was added to the RNA solution, and the mixture was subjected to electrophoresis in a $5 \%$ polyacrylamide gel with $7 \mathrm{M}$ urea at $70^{\circ} \mathrm{C}$. The band of $\sim 260$ bases corresponding to NRAS F-RNA was cut out, and the RNA was purified by ethanol precipitation after extraction in TE buffer by rotation at $4{ }^{\circ} \mathrm{C}$ for $2 \mathrm{~h}$. The mixtures of $2 \mu \mathrm{M} \mathrm{ZnAPC}$ and $0.1 \mu \mathrm{M}$ RNA in a buffer consisting of $50 \mathrm{mM}$ MES-LiOH (pH 7) and $100 \mathrm{mM} \mathrm{KCl}$ were heated to $90^{\circ} \mathrm{C}$ for $5 \mathrm{~min}$ and gently cooled to $25^{\circ} \mathrm{C}$ at $0.5^{\circ} \mathrm{C} \mathrm{min}{ }^{-1}$. After photoirradiation of the mixtures in a quartz cell with $0.1 \mathrm{~cm}$ path length, a 1.5 -fold volume of a stop solution was added. The samples containing 0.6 pmol RNA were then analysed by electrophoresis in a $15 \%$ polyacrylamide gel with $7 \mathrm{M}$ urea at $70^{\circ}$ C. After that, RNAs in the gel were transferred for $1 \mathrm{~h}$ at $100 \mathrm{~mA}$ in a cold room to a Hybond $\mathrm{N}^{+}$membrane (Amersham Biosciences) using $0.5 \times \mathrm{TBE}$ (Tris-borateEDTA) and fixed by UV irradiation for $3 \mathrm{~min}$. The membrane was washed with washing buffer and then blocked with blocking buffer for $30 \mathrm{~min}$. After incubation with anti-DIG-AP (Roche Biochemicals, 12039672910; 1:10,000) for $30 \mathrm{~min}$ at room temperature, the membrane was washed with washing buffer and incubated with detection buffer for $30 \mathrm{~min}$. The bound antibodies were visualised with a chemiluminescent substrate, CDP-Star (Roche Biochemicals) and subsequently detected by exposing blots to X-ray film (Fujifilm).

Evaluation of the dissociation constant. Absorption spectra for $2 \mu \mathrm{M} \mathrm{ZnAPC} \mathrm{or}$ $2 \mu \mathrm{M}$ FeAPC at various concentrations of RNA or DNA in a buffer consisting of $50 \mathrm{mM}$ MES- $\mathrm{LiOH}(\mathrm{pH} 7)$ and $100 \mathrm{mM} \mathrm{KCl}$ were recorded from 550 to $750 \mathrm{~nm}$. A Shimadzu UV-1800 spectrophotometer connected to a Shimadzu TMSPC-8 thermoprogrammer (Shimadzu, Kyoto, Japan) was used with a quartz cell with $1 \mathrm{~cm}$ path length. Before measurement, each sample was heated to $90^{\circ} \mathrm{C}$ for $5 \mathrm{~min}$ and gently cooled to $25^{\circ} \mathrm{C}$ at $0.5^{\circ} \mathrm{C} \mathrm{min}{ }^{-1}$

The dissociation constants $\left(K_{\mathrm{d}}\right)$ of ZnAPC with RNA or DNA oligonucleotides were evaluated by a curve-fitting procedure for the plot of $\Delta \mathrm{Abs}$ [ = (absorbance at $680 \mathrm{~nm}$ in the presence of the oligonucleotide) minus (absorbance at $680 \mathrm{~nm}$ in the absence of the oligonucleotide)] versus concentration of the oligonucleotide by means of the following equation at $25^{\circ} \mathrm{C}$ :

$$
\Delta \mathrm{Abs}=\Delta \mathrm{Abs}_{\max } \times[\text { oligonucleotide }] /\left(K_{\mathrm{d}}+[\text { oligonucleotide }]\right)
$$

where $\Delta \mathrm{Abs}_{\max }$ is the maximum difference in $\Delta \mathrm{Abs}$, and [oligonucleotide] is concentration of the added oligonucleotide. Note that the values of $\Delta \mathrm{Abs}_{\max }$ for BCL2 RNA and VEGF RNA were adjusted to the same value as that for NRAS RNA to evaluate $K_{\mathrm{d}}$ values of ZnAPC because the $\triangle \mathrm{Abs}_{\max }$ values for these RNAs were too small to fit the data under our experimental conditions.

Evaluation of fluorescence lifetime. The fluorescencedecay curves of $2 \mu \mathrm{M}$ $\mathrm{ZnAPC}$ or FeAPC in the presence or absence of $10 \mu \mathrm{M}$ NRAS RNA or NRAS DNA was recorded on a fluorescence lifetime spectrometer (Quantaurus-Tau, C11567, Hamamatsu Photonics, Shizuoka, Japan) equipped with a photon counting unit (TDC unit, M12977-01, Hamamatsu Photonics). The decay curve measurements were carried out in a buffer consisting of $50 \mathrm{mM}$ MES-LiOH (pH 7) and $100 \mathrm{mM}$ $\mathrm{KCl}$ with or without $30 \mathrm{wt} \% \mathrm{DMF}$ at room temperature. The fluorescence lifetime was evaluated by a curve-fitting system (U11487-01, Hamamatsu Photonics).

Cell culture. MCF-7 human breast cancer cells provided by the American Type Culture Collection (ATCC) were cultured in Dulbecco's modified Eagle's medium (Nissui Pharmaceutical) supplemented with 10\% of foetal bovine serum (SigmaAldrich) and $1 \%$ of a penicillin/streptomycin solution (Wako Pure Chemical Industries).

Immunoblot analysis. Cells cultured on $60 \mathrm{~mm}$ dishes were disrupted with lysis buffer $(50 \mathrm{mM}$ Tris-HCl pH 7.4, $150 \mathrm{mM} \mathrm{NaCl}, 1 \%$ Triton X-100, 1\% SDS, $10 \mathrm{mM}$ EDTA, $1 \mathrm{mM} \mathrm{Na}_{3} \mathrm{VO} 4,10 \mathrm{mM} \mathrm{NaF}$, and a protease inhibitor cocktail [PIC; Nacalai Tesque]) and then centrifuged at $20,000 \times g$ for $10 \mathrm{~min}$ after sonication. The supernatants served as total cell extracts and were subjected to sodium dodecyl sulphate polyacrylamide gel electrophoresis (SDS-PAGE). Proteins were transferred to PVDF membranes and blocked for 30 min with 5\% low-fat milk (SigmaAldrich) in TBS-T before the addition of primary antibodies. After incubation overnight at $4{ }^{\circ} \mathrm{C}$ or one hour at room temperature, the membrane was washed with TBS-T and incubated with an HRP-conjugated secondary antibody for 30 min. Bound antibodies were visualised with the HRP Chemiluminescent Reagent (Perkin Elmer) and subsequently detected by exposing blots to X-ray film (Fujifilm). Uncropped scans of immunoblots are shown in Supplementary Figure 10.

Real-time PCR. Cells were cultured on $60 \mathrm{~mm}$ dishes. Total RNA was extracted with the NucleoSpin RNA Plus Kit (Takara Bio Inc.), and cDNA was prepared with the PrimeScript 1st strand cDNA Synthesis Kit (Takara Bio Inc.). Real-time PCR analysis was performed on a StepOnePlus Real-Time PCR System (Applied
Biosystems, Foster City, CA, USA). Conditions for each transcript were as follows: $1 \mathrm{~min}$ at $95^{\circ} \mathrm{C}$, then $40 \mathrm{cycles}$ at $95^{\circ} \mathrm{C}$ for $15 \mathrm{~s}$ and $55^{\circ} \mathrm{C}$ for $1 \mathrm{~min}$. The following primers were used: human NRAS forward $5^{\prime}$-CAGAGGCAGTGGAGC TTGA $-3^{\prime}$ and reverse $5^{\prime}$-GCTTTTCCCAACACCACCT- $3^{\prime 64}$ and human B2M forward $5^{\prime}$-GCATTCCTGAAGCTGACA-3' and reverse $5^{\prime}$-CGTGAGTAAACCT GAATCTTT- $3^{\prime}$.

Circular dichroism spectra. CD spectra of oligonucleotides were measured for 20 $\mathrm{uM}$ oligonucleotide in the buffer consisting of $50 \mathrm{mM}$ MES-LiOH (pH 7) and 100 $\mathrm{mM} \mathrm{KCl}$ using a Jasco J-820 specroplarimeter (JASCO, Tokyo, Japan) with a quartz cell with $0.1 \mathrm{~cm}$ path length. Before measurement, each sample was heated to $90^{\circ} \mathrm{C}$ for $5 \mathrm{~min}$ and gently cooled to $25^{\circ} \mathrm{C}$ at $0.5^{\circ} \mathrm{C} \mathrm{min}-1$.

Fluorescence microscopy. Cells were cultured on a $35 \mathrm{~mm}$ glass bottom dish (Matsunami Glass Ind., Ltd.). ZnAPC incorporated into the cells was visualised because of its autofluorescence (ex: $488 \mathrm{~nm}$ and $\mathrm{em}$ : $>630 \mathrm{~nm}$ ). Images were acquired using a confocal microscope (LSM700; Zeiss) and then analysed in the ImageJ software (NIH).

Statistical analysis. Statistical analysis of data was performed by unpaired Student's two-sided $t$-test.

Data availability. The cell lines and all data supporting the findings of this study are available from the authors upon reasonable request.

Received: 12 January 2018 Accepted: 18 May 2018

Published online: 11 June 2018

\section{References}

1. Dolmans, D. E., Fukumura, D. \& Jain, R. K. Photodynamic therapy for cancer. Nat. Rev. Cancer 3, 380-387 (2003).

2. Agostinis, P. et al. Photodynamic therapy of cancer: an update. CA Cancer J. Clin. 61, 250-281 (2011).

3. Ethirajan, M., Chen, Y., Joshi, P. \& Pandey, R. K. The role of porphyrin chemistry in tumor imaging and photodynamic therapy. Chem. Soc. Rev. 40, 340-362 (2011)

4. Castano, A. P., Mroz, P. \& Hamblin, M. R. Photodynamic therapy and antitumour immunity. Nat. Rev. Cancer 6, 535-545 (2006).

5. Sternberg, E. D., Dolphin, D. \& Bruckner, C. Porphyrin-based photosensitizers for use in photodynamic therapy. Tetrahedron 54, 4151-4202 (1998).

6. Bonnett, R. Photosensitizers of the porphyrin and phthalocyanine series for photodynamic therapy. Chem. Soc. Rev. 24, 19-33 (1995).

7. Achilefu, S. et al. Synergistic effects of light-emitting probes and peptides for targeting and monitoring integrin expression. Proc. Natl Acad. Sci. USA 102, 7976-7981 (2005).

8. Wachter, E., Heidary, D. K., Howerton, B. S., Parkin, S. \& Glazer, E. C. Lightactivated ruthenium complexes photobind DNA and are cytotoxic in the photodynamic therapy window. Chem. Commun. 48, 9649-9651 (2012).

9. Xiang, H., Cheng, J., Ma, X., Zhou, X. \& Chruma, J. J. Near-infrared phosphorescence: materials and applications. Chem. Soc. Rev. 42, 6128-6185 (2013).

10. Faudale, M., Cogoi, S. \& Xodo, L. E. Photoactivated cationic alkyl-substituted porphyrin binding to g4-RNA in the 5'-UTR of KRAS oncogene represses translation. Chem. Commun. 48, 874-876 (2012).

11. Rapozzi, V. et al. Anticancer activity of cationic porphyrins in melanoma tumour-bearing mice and mechanistic in vitro studies. Mol. Cancer 13, 75 (2014).

12. Rahmanzadeh, R. et al. Ki-67 as a molecular target for therapy in an in vitro three-dimensional model for ovarian cancer. Cancer Res. 70, 9234-9242 (2010).

13. Membrino, A. et al. Cellular uptake and binding of guanidine-modified phthalocyanines to KRAS/HRAS G-quadruplexes. Chem. Commun. 46, 625-627 (2010).

14. Ledford, H. Cancer: the Ras renaissance. Nature 520, 278-280 (2015).

15. Boespflug, A., Caramel, J., Dalle, S. \& Thomas, L. Treatment of NRASmutated advanced or metastatic melanoma: rationale, current trials and evidence to date. Ther. Adv. Med. Oncol. 9, 481-492 (2017).

16. Ostrem, J. M., Peters, U., Sos, M. L., Wells, J. A. \& Shokat, K. M. K-Ras(G12C) inhibitors allosterically control GTP affinity and effector interactions. Nature 503, 548-551 (2013).

17. Hunter, J. C. et al. In situ selectivity profiling and crystal structure of SML-873-1, an active site inhibitor of oncogenic K-Ras G12C. Proc. Natl Acad. Sci. USA 111, 8895-8900 (2014). 
18. Lim, S. M. et al. Therapeutic targeting of oncogenic K-Ras by a covalent catalytic site inhibitor. Angew. Chem. Int. Ed. Engl. 53, 199-204 (2014).

19. Davis, J. T. G-quartets 40 years later: from $5^{\prime}$-GMP to molecular biology and supramolecular chemistry. Angew. Chem. Int. Ed. Engl. 43, 668-698 (2004).

20. Bochman, M. L., Paeschke, K. \& Zakian, V. A. DNA secondary structures: stability and function of G-quadruplex structures. Nat. Rev. Genet. 13, 770-780 (2012).

21. Kumari, S., Bugaut, A., Huppert, J. L. \& Balasubramanian, S. An RNA Gquadruplex in the $5^{\prime}$ UTR of the NRAS proto-oncogene modulates translation. Nat. Chem. Biol. 3, 218-221 (2007).

22. Cammas, A. et al. Stabilization of the G-quadruplex at the VEGF IRES represses cap-independent translation. RNA Biol. 12, 320-329 (2015).

23. Shahid, R., Bugaut, A. \& Balasubramanian, S. The BCL-2 $5^{\prime}$ untranslated region contains an RNA G-quadruplex-forming motif that modulates protein expression. Biochemistry 49, 8300-8306 (2010).

24. Maizels, N. \& Gray, L. T. The G4 genome. PLoS Genet. 9, e1003468 (2013).

25. Chambers, V. S. et al. High-throughput sequencing of DNA G-quadruplex structures in the human genome. Nat. Biotechnol. 33, 877-881 (2015).

26. Cogoi, S. \& Xodo, L. E. G-quadruplex formation within the promoter of the KRAS proto-oncogene and its effect on transcription. Nucleic Acids Res. 34, 2536-2549 (2006).

27. Patel, D. J., Phan, A. T. \& Kuryavyi, V. Human telomere, oncogenic promoter and 5'-UTR G-quadruplexes: diverse higher order DNA and RNA targets for cancer therapeutics. Nucleic Acids Res. 35, 7429-7455 (2007).

28. Rhodes, D. \& Lipps, H. J. G-quadruplexes and their regulatory roles in biology. Nucleic Acids Res. 43, 8627-8637 (2015).

29. Wolfe, A. L. et al. RNA G-quadruplexes cause eIF4A-dependent oncogene translation in cancer. Nature 513, 65-70 (2014).

30. Arora, A. et al. Inhibition of translation in living eukaryotic cells by an RNA G-quadruplex motif. RNA 14, 1290-1296 (2008).

31. Bugaut, A. \& Balasubramanian, S. 5'-UTR RNA G-quadruplexes: translation regulation and targeting. Nucleic Acids Res. 40, 4727-4741 (2012).

32. Agarwala, P., Pandey, S. \& Maiti, S. The tale of RNA G-quadruplex. Org. Biomol. Chem. 13, 5570-5585 (2015).

33. Monchaud, D. \& Teulade-Fichou, M. P. A hitchhiker's guide to G-quadruplex ligands. Org. Biomol. Chem. 6, 627-636 (2008).

34. Neidle, S. Human telomeric G-quadruplex: the current status of telomeric Gquadruplexes as therapeutic targets in human cancer. FEBS J. 277, 1118-1125 (2010).

35. Balasubramanian, S., Hurley, L. H. \& Neidle, S. Targeting G-quadruplexes in gene promoters: a novel anticancer strategy? Nat. Rev. Drug Discov. 10, 261-275 (2011).

36. Yaku, H., Murashima, T., Miyoshi, D. \& Sugimoto, N. In vitro assays predictive of telomerase inhibitory effect of G-quadruplex ligands in cell nuclei. J. Phys. Chem. B 118, 2605-2614 (2014).

37. Dixon, I. M. et al. A G-quadruplex ligand with 10000 -fold selectivity over duplex DNA. J. Am. Chem. Soc. 129, 1502-1503 (2007).

38. Ginnari-Satriani, L., Casagrande, V., Bianco, A., Ortaggi, G. \& Franceschin, M. A hydrophilic three side-chained triazatruxene as a new strong and selective G-quadruplex ligand. Org. Biomol. Chem. 7, 2513-2516 (2009).

39. Gabelica, V. et al. Multiple and cooperative binding of fluorescence light-up probe thioflavin T with human telomere DNA G-quadruplex. Biochemistry 52, 5620-5628 (2013).

40. Yaku, H., Murashima, T., Miyoshi, D. \& Sugimoto, N. Anionic phthalocyanines targeting G-quadruplexes and inhibiting telomerase activity in the presence of excessive DNA duplexes. Chem. Commun. 46, 5740-5742 (2010).

41. Yaku, H., Fujimoto, T., Murashima, T., Miyoshi, D. \& Sugimoto, N. Phthalocyanines: a new class of G-quadruplex-ligands with many potential applications. Chem. Commun. 48, 6203-6216 (2012).

42. Yaku, H. et al. Study on effects of molecular crowding on G-quadruplexligand binding and ligand-mediated telomerase inhibition. Methods 64, 19-27 (2013).

43. Isci, U. et al. Site-selective formation of an iron(IV)-oxo species at the more electron-rich iron atom of heteroleptic mu-nitrido diiron phthalocyanines. Chem. Sci. 6, 5063-5075 (2015).

44. Bletsa, E., Solakidou, M., Louloudi, M. \& Deligiannakis, Y. Oxidative catalytic evolution of redox- and spin-states of a Fe-phthalocyanine studied by EPR. Chem. Phys. Lett. 649, 48-52 (2016).

45. Tuncel, S. et al. A set of highly water-soluble tetraethyleneglycol-substituted $\mathrm{Zn}(\mathrm{II})$ phthalocyanines: synthesis, photochemical and photophysical properties, interaction with plasma proteins and in vitro phototoxicity. Dalton Trans. 40, 4067-4079 (2011).
46. Liu, J. Y., Jiang, X. J., Fong, W. P. \& Ng, D. K. Highly photocytotoxic 1,4dipegylated zinc(II) phthalocyanines. Effects of the chain length on the in vitro photodynamic activities. Org. Biomol. Chem. 6, 4560-4566 (2008).

47. Zorlu, Y. et al. Glycerol and galactose substituted zinc phthalocyanines. Synthesis and photodynamic activity. Photochem. Photobiol. Sci. 8, 312-318 (2009).

48. Setsukinai, K., Urano, Y., Kakinuma, K., Majima, H. J. \& Nagano, T. Development of novel fluorescence probes that can reliably detect reactive oxygen species and distinguish specific species. J. Biol. Chem. 278, 3170-3175 (2003).

49. Fasano, O., Birnbaum, D., Edlund, L., Fogh, J. \& Wigler, M. New human transforming genes detected by a tumorigenicity assay. Mol. Cell Biol. 4, 1695-1705 (1984)

50. Segalla, A. et al. Photophysical, photochemical and antibacterial photosensitizing properties of a novel octacationic $\mathrm{Zn}(\mathrm{II})$-phthalocyanine. Photochem. Photobiol. Sci. 1, 641-648 (2002).

51. Brozek-Pluska, B., Jarota, A., Kurczewski, K. \& Abramczyk, H. Photochemistry of tetrasulphonated zinc phthalocyanine in water and DMSO solutions by absorption, emission, Raman spectroscopy and femtosecond transient absorption spectroscopy. J. Mol. Struct. 924, 338-346 (2009).

52. Ashokkumar, R., Kathiravan, A. \& Ramamurthy, P. Aggregation behaviour and electron injection/recombination dynamics of symmetrical and unsymmetrical Zn-phthalocyanines on $\mathrm{TiO}_{2}$ film. Phys. Chem. Chem. Phys. 16, 1015-1021 (2014)

53. van Leeuwen, M., Beeby, A., Fernandes, I. \& Ashworth, S. H. The photochemistry and photophysics of a series of alpha octa(alkyl-substituted) silicon, zinc and palladium phthalocyanines. Photochem. Photobiol. Sci. 13, 62-69 (2014).

54. Tombe, S., Antunes, E. \& Nyokong, T. The photophysical and photochemical behaviour of coumarin-derivatized zinc phthalocyanine when conjugated with gold nanoparticles and electrospun into polymer fibers. New J. Chem. 37, 679-689 (2013).

55. Wei, C., Han, G., Jia, G., Zhou, J. \& Li, C. Study on the interaction of porphyrin with G-quadruplex DNAs. Biophys. Chem. 137, 19-23 (2008)

56. Sazanovich, I. V., Petrov, E. P. \& Chirvony, V. S. Interaction of cationic 5,10,15,20-tetrakis(4-N-methyl pyridyl) porphyrin with mono- and polynucleotides: a study by picosecond fluorescence spectroscopy. Opt. Spectrosc. 100, 209-218 (2006).

57. Jasuja, R., Jameson, D. M., Nishijo, C. K. \& Larsen, R. W. Singlet excited state dynamics of tetrakis(4-N-methylpyridyl)porphine associated with DNA nucleotides. J. Phys. Chem. B 101, 1444-1450 (1997).

58. Chirvony, V. S., Galievsky, V. A., Kruk, N. N., Dzhagarov, B. M. \& Turpin, P. Y. Photophysics of cationic 5,10,15,20-tetrakis-(4-N-methylpyridyl)porphyrin bound to DNA, $[$ poly $(\mathrm{dA}-\mathrm{dT})](2)$ and $[\operatorname{poly}(\mathrm{dG}-\mathrm{dC})](2)$ : on a possible charge transfer process between guanine and porphyrin in its excited singlet state. $J$. Photoch. Photobio. B 40, 154-162 (1997).

59. Shi, Z. L., Zhang, X. F., Cheng, R., Zhang, Q. \& Jin, Y. High-throughout identification of telomere-binding ligands based on photo-induced electron transfer. RSC Adv. 6, 16256-16262 (2016).

60. Li, X., Sinks, L. E., Rybtchinski, B. \& Wasielewski, M. R. Ultrafast aggregateto-aggregate energy transfer within self-assembled light-harvesting columns of zinc phthalocyanine tetrakis(perylenediimide). J. Am. Chem. Soc. 126, 10810-10811 (2004).

61. Lu, X. \& Kang, Y. Hypoxia and hypoxia-inducible factors: master regulators of metastasis. Clin. Cancer Res. 16, 5928-5935 (2010).

62. Wigerup, C., Pahlman, S. \& Bexell, D. Therapeutic targeting of hypoxia and hypoxia-inducible factors in cancer. Pharmacol. Ther. 164, 152-169 (2016).

63. Sugimoto, N., Nakano, M. \& Nakano, S. Thermodynamics-structure relationship of single mismatches in RNA/DNA duplexes. Biochemistry 39, 11270-11281 (2000).

64. de Launay, D. et al. Silencing the expression of Ras family GTPase homologues decreases inflammation and joint destruction in experimental arthritis. Am. J. Pathol. 177, 3010-3024 (2010).

\section{Acknowledgements}

We thank Dr. Tamaki Endoh for discussion, and Ms. Sachi Wakasugi for carrying out purification of DIG-labelled RNA. This work was supported by JSPS KAKENHI (Grant Numbers 16K14042 and 15H03840 for K.K. and D.M.), especially a Grant-in-Aid for Scientific Research on Innovative Areas "Chemistry for Multimolecular Crowding Biosystems" (17H06351 for D.M. and N.S.), the Naito Foundation Natural Science Scholarship for D.M. and the Asahi Glass Foundation Research Grant for D.M.

\section{Author contributions}

K.K., H.T.-K., N.S. and D.M. designed the study. K.K. and D.M. with contributions from W.S., T.Y., K.M., K.I., K.T., T.T., K.A. and H.T.-K. performed all experiments. K.K. and D.M. wrote the manuscript. 


\section{Additional information}

Supplementary Information accompanies this paper at https://doi.org/10.1038/s41467018-04771-y.

Competing interests: The authors declare no competing interests.

Reprints and permission information is available online at http://npg.nature.com/ reprintsandpermissions/

Publisher's note: Springer Nature remains neutral with regard to jurisdictional claims in published maps and institutional affiliations. adaptation, distribution and reproduction in any medium or format, as long as you give appropriate credit to the original author(s) and the source, provide a link to the Creative Commons license, and indicate if changes were made. The images or other third party material in this article are included in the article's Creative Commons license, unless indicated otherwise in a credit line to the material. If material is not included in the article's Creative Commons license and your intended use is not permitted by statutory regulation or exceeds the permitted use, you will need to obtain permission directly from the copyright holder. To view a copy of this license, visit http://creativecommons.org/ licenses/by/4.0/.

(C) The Author(s) 2018 